\title{
GENDER AND THE EVALUATION OF HUMOR AT WORK
}

\author{
Jonathan B. Evans \\ University of Arizona \\ Department of Management and Organizations \\ 1130 E. Helen Street \\ McClelland Hall, Room 405 \\ Tucson, AZ 85721 \\ (520) 621-1869 \\ jbevans@email.arizona.edu \\ Jerel E. Slaughter \\ University of Arizona \\ Department of Management and Organizations \\ 1130 E. Helen Street \\ McClelland Hall, Room 405 \\ Tucson, AZ 85721 \\ (520) 621-7632 \\ jslaught@email.arizona.edu \\ Aleksander P.J. Ellis \\ University of Arizona \\ Department of Management and Organizations \\ 1130 E. Helen Street \\ McClelland Hall, Room 405 \\ Tucson, AZ 85721 \\ (520) 621-7461 \\ aleks@email.arizona.edu \\ Jessi M. Rivin \\ University of Colorado Boulder \\ Organizational Behavior and Information Systems \\ Koelbel Building, Room 111 \\ 995 Regent Drive \\ Boulder, CO 80309 \\ (818) 730-2200 \\ jessi.rivin@colorado.edu
}

Author's note: Portions of this paper will be presented at the $34^{\text {th }}$ Annual Conference of the Society for Industrial and Organizational Psychology (SIOP), Washington, D.C. We are grateful to Dianne Eldridge for sharing the experiences she has had as a leader at work that provided the genesis for this project. 
(C) 2019, American Psychological Association. This paper is not the copy of record and may not exactly replicate the final, authoritative version of the article. Please do not copy or cite without authors' permission. The final article will be available, upon publication, via its DOI: 10.1037/apl0000395 
Gender and the Evaluation of Humor at Work 


\begin{abstract}
Although research has added to our understanding of the positive and negative effects of the use of humor at work, scholars have paid little attention to characteristics of the humor source. We argue that this is an important oversight, particularly in terms of gender. Guided by parallelconstraint-satisfaction theory (PCST), we propose that gender plays an important role in understanding when using humor at work can have costs for the humor source. Humor has the potential to be interpreted as either a functional or disruptive work behavior. Based on PCST, we argue that gender stereotypes constrain the interpretation of observed humor such that humor expressed by males is likely to be interpreted as more functional and less disruptive compared to humor expressed by females. As a result, humorous males are ascribed higher status compared to non-humorous males, while humorous females are ascribed lower status compared with nonhumorous females. These differences have implications for subsequent performance evaluations and assessments of leadership capability. Results from an experiment with 216 participants provides support for the moderated mediation model. Theoretical and practical implications are discussed.
\end{abstract}

Keywords: humor, gender, status, leadership, performance evaluation 
Humor, defined as expressions that are appraised by others as funny or cause others to experience amusement (Cooper, 2008; Cooper, 2005; McGraw \& Warren, 2010), is considered a universal behavior that exists in nearly all cultures (Apte, 1985). The benefits of using humor include reduced stress (Bizi, Keinan, \& Beit-Hallahmi, 1988; Martin \& Dobbin, 1989; Nezu, Nezu, \& Blissett, 1988), improved social interactions (Martin, Puhlik-Doris, Larsen, Gray, \& Weir, 2003), and increased positive affect and motivation (Kuiper, McKenzie, \& Belanger, 1995). At work, the benefits of leader humor include increased employee creativity (Csikszentmihalyi, 1996; O’Quin \& Derks, 1997), subordinate job satisfaction and commitment (Decker, 1987), and individual and unit-level performance (Avolio, Howell, \& Sosik, 1999). In sum, humor appears to have positive consequences, in both work and nonwork contexts.

However, recent research has identified potential downsides for humor at work. Bitterly, Brooks, and Schweitzer (2017) considered the riskiness of humor, and found evidence that unsuccessful humor attempts can reduce status. Yam, Christian, Wei, Liao, and Nai (2018) found that the violation of norms that accompanies humor (McGraw \& Warren, 2010) signaled the acceptance of abnormal behavior and led to higher levels of employee deviance, especially when the humor was aggressive. Other scholars have suggested that humor may actually be appropriated as a tool to control employee feelings and attitudes (Fineman, 2006).

The purpose of this investigation is to increase our understanding of when humor can be beneficial or costly at work. Notably, past research has ignored the potential impact of individual characteristics of the humor source. We focus on gender and examine how humorous men are evaluated differently from humorous women. Using parallel-constraint-satisfaction theory (Kunda \& Thagard, 1996), which posits that stereotypes affect the interpretation of behavior, we argue that men will benefit, while women will be penalized, when using humor at work. 
Specifically, women's use of humor will trigger lower ratings of status compared to nonhumorous women, while men's use of humor will trigger higher ratings of status compared to non-humorous men. We expect that these differences will affect subsequent performance evaluations and assessments of leadership capability as shown in Figure 1.

This paper contributes to the humor, gender, and leadership literatures by highlighting the importance of the humor source. First, we add to the humor literature by identifying gender as an important boundary condition. The effects of humor are determined not only by type of humor, but also by characteristics of the source. Second, we add to the gender literature by examining the role of gender stereotypes in a unique context and show how people's expectations for men and women can influence their interpretation of a generally desirable behavior, such as acting in a humorous fashion. Third, we add to the leadership literature. Considerable research has sought to determine whether gender affects leadership evaluations. However, results have been equivocal, with evidence supporting the existence of both prejudice against female leaders and a female leadership advantage (Eagly, Karau, \& Makhijani, 1995; Eagly, Makhijani, \& Klonsky, 1992; Koenig, Eagly, Mitchell, \& Ristikari, 2011; Rosette \& Tost, 2010). Leader behavior has been identified as an important moderator, and in the following section we posit that humor represents an important behavioral category that can elicit gender differences.

\section{Humor and the Role of Gender}

Research has shown that people benefit from being humorous because observers respond positively (Mesmer-Magnus, Glew, \& Viswesvaran, 2012). Recently, Bitterly et al. (2017) found that successful humor has the potential to increase status, which is the level of respect and esteem that an individual possesses in a group (Anderson \& Kilduff, 2009). As argued by Bitterly et al., this is a result of successful humor signaling high confidence and competence. 
However, it is notable that they manipulated humor using exclusively male confederates. The fact that gender has not been considered is important because gender stereotypes can serve as shortcuts for forming impressions (Heilman, 2012). Descriptive gender stereotypes, which comprise expectations about how women and men behave, are widely shared and are often automatically activated (Hentschel, Heilman, \& Peus, 2013). Accordingly, considerable research has shown that the same behavior performed by men at work does not produce the same effect when performed by women (Heilman \& Chen, 2005; Motro \& Ellis, 2017).

Parallel-constraint-satisfaction theory (PCST) frames our arguments for how gender affects the evaluation of humor. PCST explains how different categories of information are integrated to influence impression formation. The key tenet is that different information sources, such as stereotypes and observed behavior, are evaluated simultaneously (i.e., in parallel) and jointly constrain person perception. One proposition is that when behavior can be interpreted ambiguously, stereotypes influence the interpretation so that it satisfies expectations. Kunda and Thagard (1996) highlighted this idea by drawing attention to studies showing that a Caucasian person elbowing another person was interpreted as a jovial push, but the same action by an African-American person was interpreted as a violent shove (Sagar \& Schofield, 1980). Impression formation results from the joint influence of both the stereotype and the observed behavior, which is likely to be interpreted in a way that aligns with expectations. Therefore, the stereotype of aggression that is associated with African-Americans (Blair, Judd, \& Fallman, 2004) increases the likelihood that the elbow nudge will be interpreted as a violent shove. Various propositions of PCST have been supported across a number of studies (Koch, D'Mello, \& Sackett, 2015; Kunda \& Sherman-Williams, 1993; Sagar \& Schofield, 1980). 
Like an elbow nudge, humor is a potentially ambiguous behavior. It can be viewed as either functional or disruptive (Cann \& Matson, 2014; Finkelstein, Cerrentano, \& Voyles, 2016). A functional perspective suggests that humor is a tool that can facilitate the accomplishment of work (Caudron, 1992; Malone, 1980; Newstrom, 2002). For example, humor can be used to reframe problems so that they seem less troubling and can diffuse negative emotions (Grugulis, 2002). However, a disruptive perspective views humor as entertainment designed for amusement, which conflicts with the serious nature of business (Duncan, Smeltzer, \& Leap, 1990). This perspective suggests that humorous individuals at work lack dedication (Taylor \& Bain, 2003; Westwood \& Johnston, 2013). According to PCST, gender stereotypes have the potential to influence the degree to which humor is viewed as functional or disruptive.

The defining characteristic of the male stereotype is agency (Diekman \& Eagly, 2000; Heilman, 2012). Agentic behavior expectations include both an achievement orientation (e.g., ambitious, task-focused) and an inclination toward rationality (e.g., analytical, logical). These aspects of the male stereotype reinforce a positive interpretation of humor. According to PCST, coherence between expectations of high agency and observations of humor can be maintained by interpreting humor as contributing to work outcomes. Thus, for men, we expect that the effect of humor will be similar to that observed by Bitterly et al. (2017), in that it will be evaluated positively because it is seen as more functional compared to humor expressed by women.

There are two reasons why we expect humor from women to be interpreted differently. First, female stereotypes include expectations of low agency, achievement, and rationality (Fiske, Cuddy, Glick, \& Xu, 2002; Heilman, Block, \& Stathatos, 1997). This suggests that the proposed positive interpretation for men does not apply for women. Second, working women are stereotyped as having lower dedication to work (Rivera \& Tilcsik, 2016), due to their association 
with family responsibilities and the perception that women cannot be simultaneously dedicated to both work and family (Blair-Loy, 2004). Because a disruptive interpretation of humor signals a lower dedication to getting things done, maximum coherence between female stereotypes and observed behavior can be maintained when humor is interpreted as disruptive.

These arguments suggest that gender plays an important role in the relationship between humor and status. Within social groups, respect and prestige are afforded to individuals who demonstrate superior abilities or are considered valuable (Anderson \& Kilduff, 2009). Because of the high social value of competence, behaviors that signal competence increase status (Anderson, Brion, Moore, \& Kennedy, 2012; Chen, Peterson, Phillips, Podolny, \& Ridgeway, 2012). Consistent with the findings of Bitterly et al. (2017), humor interpreted as functional is likely to signal competence, and we expect a positive relationship between humor and status for men. Similarly, because of the value placed on sacrificing individual objectives and being dedicated to the performance of the group, when humor is interpreted as more disruptive it is likely to signal a lack of dedication, which has been shown to reduce status (Hardy \& Van Vugt, 2006; Willer, 2009). Accordingly, we expect that a disruptive interpretation of humor will reduce status ratings and result in a negative relationship between humor and status for women.

Hypothesis 1. Humor interacts with gender to influence perceptions of status, such that the effect of humor on status perceptions is positive for men and negative for women.

\section{Effects on Leadership Evaluations}

We used PCST, which suggests that the integration of different sources of information will affect person perception, to argue that humor and gender will significantly affect the proximal outcome of status perceptions. We next sought to consider how these differential status perceptions might relate to important distal outcomes. Status hierarchies are self-reinforcing in 
nature, such that individuals who are afforded higher status are more likely to receive benefits that enhance their hierarchical position (Magee \& Galinsky, 2008). Therefore, we considered how status might relate to outcomes likely to increase future success within organizations: higher performance evaluations and assessments of leadership capability. Performance evaluations represent individual judgments regarding employee performance, and assessment of leadership capability refers to the appraisal of employee potential to successfully fulfill leadership positions.

The self-reinforcing nature of status suggests that higher status individuals are likely to receive the benefit of higher performance evaluations. Individuals who are respected or prestigious, due to either socially significant characteristics or behavioral patterns, tend to receive the added benefit of positive performance evaluations, regardless of actual performance. For example, Darley and Gross (1983) found that when participants were told that a young girl taking a test was high in socioeconomic status, they thought she was smarter and achieved a higher score than when they were told she was low in socioeconomic status, even though participants watched the same girl take the same test in both conditions. Thus, high status has the potential to produce superior performance evaluations compared to low status, even when the behavior is the same (Correll \& Ridgeway, 2006; Sande, Ellard, \& Ross, 1986).

Regarding assessment of leadership capability, decision makers tend to look to highly respected others to fill leadership positions (Ellemers, De Gilder, \& Haslam, 2004). This is because group members are likely to conclude that high status individuals (i.e., individuals who embody desired characteristics) can improve team survival (Cialdini et al., 1976; Graffin, Wade, Porac, \& McNamee, 2008). Respect within the group is expected to increase the ability to be influential (Blader \& Chen, 2014; Fiske \& Berdahl, 2007; Magee \& Galinsky, 2008), which increases the likelihood of being viewed as a leader. Thus, we expect that higher ratings of status 
will result in both higher performance evaluations and leadership capability assessments, and we hypothesize the following regarding the effect of humor and gender:

Hypothesis 2. The indirect effect of humor on (a) performance evaluation and (b) assessment of leadership capability through perceived status is moderated by gender, such that the indirect effect is positive for men and negative for women.

\section{METHOD}

Two samples were used to test our arguments and hypotheses. Sample 1 investigates the argument that female humor will be evaluated as more disruptive than male humor, and male humor will be evaluated as more functional than female humor. We did not test these arguments in the same analyses as the hypothesized model because humor functionality and disruptiveness would not be expected to mediate the interactive effects of gender and humor (i.e., they do not apply to situations when humor is not expressed). Sample 2 was used to test the hypotheses.

\section{Stimulus Material Development}

We developed four video recordings of a retail store manager reporting on store performance to a group of regional managers. The videos followed a 2 (humor: yes vs. no) $\times 2$ (male vs. female) between-subjects design. One actress and one actor played the role of the store manager. Each played the role with and without humor. The humor conditions included five humorous statements. Except for the humor, the script was the same in all four videos. The Appendix includes all humorous statements and a full description of the presentation.

\section{Sample 1}


Participants and Procedure. We recruited 101 adults currently residing in the United States through Amazon Mechanical Turk (MTurk; www.mturk.com) ${ }^{1}$. The final sample included 96 participants who passed the quality control questions. The average age was 34.7 years $(S D=$ 9.73) and 39\% were female. The racial makeup was 74.0\% Caucasian, 9.4\% African-American, 7.3\% Hispanic, $6.3 \%$ Asian, and 3.1\% other races. Most participants were full-time employees (70.0\%), with $17.7 \%$ self-employed and 5.2\% part-time employed. Participants worked in a wide variety of fields such as information technology (18.8\%), marketing (17.7\%), communications (9.4\%), and finance (5.2\%). Most participants reported an income between $\$ 25,000$ and $\$ 40,000$.

Participants were randomly assigned to 1 of 2 conditions (male vs. female) and were told that they would watch a video recording of a manager's presentation and then provide an evaluation. Prior to watching the video, participants reviewed a résumé of the manager, named Sam. The résumé indicated that Sam was a successful and talented manager, who had one year of experience managing a clothing store. Participants then viewed a video of either the humorous male or humorous female manager. After watching the entire video, they were instructed to evaluate the humor by responding to measures of humor disruptiveness and humor functionality, which were counterbalanced. All participants correctly identified the presenter's gender.

\section{Sample 1 Measures}

Disruptiveness. We measured the degree to which humor was disruptive with five items generated for this study $(\alpha=.97)$. Participants responded to items on a seven-point scale $(1=$ strongly disagree, 7 = strongly agree). Items included, "Sam's use of humor was disruptive," "The humor distracted from the purpose of the presentation," "The humor was harmful to the

\footnotetext{
${ }^{1}$ Data collection for studies reported in this article were approved by the institutional review board at the University of Arizona (7-11-MGMT: Gender and leader humor).
} 
presentation," "The humorous comments reflected badly on Sam," and "The humor negatively influenced the presentation effectiveness."

Functionality. We measured the degree to which humor was functional with five items generated for this study $(\alpha=.97)$. Items included, "Sam's use of humor was functional," "The humor contributed positively to the purpose of the presentation," "The humor was helpful to the presentation," "The humorous comments reflected well on Sam," and "The humor positively influenced the presentation effectiveness."

Control variables. We controlled for participant gender and attractiveness, which was rated on a seven-point scale $(1=$ very unattractive to $7=$ very attractive $)$. Average attractiveness was $4.80(S D=1.24)$ for the male condition and $5.54(S D=0.94)$ for the female condition.

\section{Sample 2}

Participants and Procedure. We recruited 231 adults currently residing in the United States through MTurk. The final sample included 216 participants who passed the quality control questions. The average age was 37.3 years $(S D=11.73)$ and $42 \%$ were female. The racial makeup of the sample was $71.8 \%$ Caucasian, 10.2\% Asian, 8.8\% African-American, 5.1\% Hispanic, and 4.2\% other. Most participants were full-time employees (63.0\%), with 14.4\% parttime employed and $16.7 \%$ self-employed. Participants worked in a wide variety of fields such as marketing and sales (12.5\%), education and training (11.1\%), information technology (8.3\%), business management (7.9\%), communications (7.9\%), and finance (7.4\%). Most participants reported an income between $\$ 25,000$ and $\$ 40,000$. Using the statistical package $\mathrm{R}$ (R. Core Team, 2017), we found that the excluded participants did not differ significantly from included participants in age, $t(229)=.60, p>.05$, gender, $\chi^{2}(2, N=231)=.01, p>.05$, minority status, $\chi^{2}(2, N=231)=.91, p>.05$, or full-time employment status, $\chi^{2}(2, N=231)=.22, p>.05$. 
Participants were randomly assigned to 1 of 4 conditions in a 2 (humor: yes vs. no) $\times 2$ (male vs. female) between-subjects design. Participants were told that the purpose of the study was to examine leadership capability and that they would watch a video of a manager's presentation and then provide an evaluation. After reviewing the résumé, participants watched the entire video before answering manipulation check questions and a measure of status. They then evaluated performance and assessed leadership capability, which were counterbalanced. The final section of the survey included control variables (see below) and demographic items.

\section{Sample 2 Measures}

Manipulation checks. All participants correctly identified the presenter's gender.

Following procedures used by Bitterly et al. (2017), we asked participants to rate the presentation on a seven-point scale $(1=$ not at all, 7 = extremely) on eight separate dimensions (engaging, funny, appropriate, entertaining, succinct, clear, memorable, effective, humorous). The items 'funny' and 'humorous' were combined to form a rating of funniness $(\alpha=.97)$. Participants rated the humor conditions as significantly funnier $(M=5.00, S D=1.64)$ than the non-humor conditions $(M=2.19, S D=1.38), t(214)=13.63, p<.001, d=1.85$.

Status. We measured status with a five-item scale $(\alpha=.96)$ adapted from Djurdjevic et al. (2017). Participants rated the degree to which items accurately reflected Sam on a seven-point scale $(1=$ very inaccurate, $7=$ very accurate $)$. Sample items included, "Sam has a great deal of prestige within the organization" and "Sam possess high status in the organization."

Performance evaluation. Performance was evaluated using a three-item scale $(\alpha=.74)$ adapted from Heilman and Chen (2005). The first question, “Overall, how would you rate Sam's performance over the past year?", was rated on a seven-point scale $(1=$ excellent to $7=$ average $)$ and reverse coded. The other two questions, "In your opinion, how likely is it that Sam will 
advance in the company?" and "Give your assessment of Sam's likelihood of success" were rated on a separate seven-point scale $(1=$ very unlikely to $7=$ very likely $)$.

Leadership capability. We measured leadership capability with a four-item scale $(\alpha=.94$ based on capabilities associated with effective leadership (e.g., Epitropaki \& Martin, 2004) and used in Rosette, Leonardelli, and Phillips (2008). Participants were asked to rate Sam's capability for a division manager role by assessing intelligence, competence, confidence, and competitiveness on a seven-point scale $(1=$ strongly disagree to $7=$ strongly agree $)$.

Control variables. We controlled for attractiveness (same measure used for Sample 1) and participant gender. The average level of attractiveness was $4.39(S D=1.40)$ for the male condition and $5.17(S D=1.40)$ for the female condition.

\section{Analytical Strategy}

In both samples we used Mplus Version 8 (Muthén \& Muthén, 1998-2017) to conduct a series of confirmatory factor analyses (CFA) to assess the factor structure of our measures. To test humor functionality and disruptiveness, we conducted a MANCOVA on Sample 1 with the statistical package R (R. Core Team, 2017). We entered actor gender as the independent variable, humor functionality and disruptiveness as dependent variables. Using Sample 2, we tested the proposed model with Mplus Version 8 (Muthén \& Muthén, 1998-2017). Following recommended procedures (Bauer, Preacher, \& Gil, 2006), we used a Monte Carlo approach using 10,000 bootstrap resamples to construct confidence intervals in estimating effects. We entered humor as the independent variable, gender as the moderator, status as the mediator, with performance evaluation and leadership capability as dependent variables. We entered employee attractiveness and participant gender as control variables in all analyses. 
For Hypothesis 1, which predicted that humor would have a negative effect on status for women and a positive effect for men, we looked at the interaction between humor and gender as a predictor of status and the conditional effects of humor on status for men and women. For Hypothesis 2, which proposed that the conditional indirect effect through status is positive for men and negative for women, we looked for evidence of moderated mediation (Preacher, Rucker, \& Hayes, 2007). Following Hayes (2015), we calculated the index of moderated mediation to examine differences between conditional indirect effects. When the index is significantly different than zero, this indicates that the conditional indirect effects are different from each other. Finally, we looked at the conditional indirect effects of humor on the dependent variables for the male and female presenter to examine support for the proposed effects.

\section{RESULTS}

\section{Disruptiveness and Functionality of Humor}

Table 1 presents means, standard deviations and correlations for Sample 1. Results of the CFA for a two-factor solution in which items loaded on separate disruptiveness and functionality factors indicated that the model departed significantly from the data, $\chi^{2}(34)=60.97, p=.003$, but fit statistics indicated good fit, comparative fit index $(\mathrm{CFI})=.98$, standardized root mean square residual $(\mathrm{SRMR})=.02$. The fit for a one-factor solution in which all items loaded on the same factor was marginal, $\chi^{2}(35)=259.49, p<.001, \mathrm{CFI}=.84, \mathrm{SRMR}=.06$. The two-factor solution provided significantly better fit than the one-factor solution, $\Delta \chi^{2}(1)=198.53, p<.001$.

Results of the MANCOVA suggested significant between-group differences, Wilk's $\Lambda$ $=.90$, multivariate $F(2,91)=4.90, p=.010, \eta^{2}=.10$. Consistent with our arguments, female humor was judged as more disruptive than male humor, $F(1,92)=4.44, p=.038, \eta^{2}=.05$. In 
contrast, male humor was judged as more functional than female humor, $F(1,92)=9.33, p$ $=.003, \eta^{2}=.09$. Thus, our argument regarding the interpretation of humor was supported.

\section{Hypothesized Model}

Table 2 presents means, standard deviations and correlations for Sample 2. The CFA results, shown in Table 3 support measure separation. The three-factor solution wherein items loaded separately on status, performance evaluation, and leadership capability fit the data well, $\chi^{2}(51)=141.38, p<.001, \mathrm{CFI}=.96, \mathrm{SRMR}=.06$, and provided the best fit to the data. The results of the hypothesized model are shown in Table 4. In support of Hypothesis 1, the interaction between humor and gender significantly predicted status, $B=-.94, S E_{B}=.31, p$ $<.001$. We found that the conditional effect of humor on status was positive for men, coefficient $=.46, S E=.22, \mathrm{CI}(.10, .83)$, and negative for women, coefficient $=-.48, S E=.25, \mathrm{CI}(-.99$, -.01). Thus, Hypothesis 1 was supported. See Figure 2 for a graph of this interaction. In support of Hypothesis 2, the indices of moderated mediation were significantly different from zero for each dependent variable (coefficients were .50 for performance evaluation and .55 for leadership capability). This indicated that the indirect effects of humor through status on each of the outcomes differed significantly for men and women. In the male condition, the indirect effect of humor on performance evaluation was positive, coefficient $=.27$, $S E=.11, \mathrm{CI}(.06, .50)$, as was the indirect effect of humor on assessment of leadership capability, coefficient $=.25, S E=.10, \mathrm{CI}(.06, .46)$. However, in the female condition, the indirect effects of humor on performance evaluation, coefficient $=-.28, S E=.15, \mathrm{CI}(-.59,-.01)$, and assessment of leadership capability, coefficient $=-.26, S E=.14$, CI $(-.56,-.01)$ were negative. Thus, Hypotheses $2 \mathrm{a}$ and $2 \mathrm{~b}$ were supported.

\section{Supplemental Analyses}


One noteworthy pattern is that humor was not significantly related to status $(r=-.00)$ or either of the outcome variables $(r=-.05$ for performance evaluations and $r=-.04$ for leadership capability). To investigate this, we compared the effects sizes of humor on status for women and men. Using statistical package R (R. Core Team, 2017), we conducted a 2 (humor: yes vs. no) $\times$ 2 (male vs. female) between-subjects analysis of covariance with status as the dependent variable and employee attractiveness and participant gender as controls. Status in the humorous male condition was significantly higher than the non-humorous male, $F(1,210)=4.43, p=.037, \eta^{2}$ $=.02$. Moreover, status in the humorous female condition was significantly lower than the nonhumorous female, $F(1,210)=4.57, p=.034, \eta^{2}=.02$. Importantly, the effect size for humor is similar for men and women. Given that the direction of the effect of humor is positive for men and negative for women, the similar effect size suggests that the two effects cancel each other, which explains the non-significant relationships with status and the outcome variables.

\section{DISCUSSION}

Research on humor at work has shown that there can be both positive (Avolio et al., 1999; Romero \& Cruthirds, 2006) and negative (Bitterly et al., 2017; Yam et al., 2018) effects. The purpose of this paper was to advance our knowledge about situations in which humor may be more versus less effective. We focused on the ambiguity of what humor signals and considered the gender of the humor source. Based on PCST, we argued that humor expressed by men would be seen as more functional than humor expressed by women, while humor expressed by women would be seen as more disruptive than humor expressed by men, leading to higher and lower perceptions of status, respectively. Status would then determine performance evaluations and assessments of leadership capability. Our results, which were supportive of our 
arguments, highlight an important boundary condition when considering the benefits of humor at work, which has implications for several literatures.

First, we contribute to the literature on humor by highlighting the importance of humor source. Current research supports the idea that the benefits of humor depend on whether the humor is self-enhancing, aggressive, or self-defeating (Galloway, 2010; Kuiper \& McHale, 2009; Yam et al., 2018). By incorporating PCST, we demonstrated that gender can determine reactions to successful humor attempts. Second, we contribute to the literature on gender in the workplace. Research in group dynamics (Heilman \& Haynes, 2005), organizational citizenship behavior (Heilman \& Chen, 2005), and career experiences (Judiesch \& Lyness, 1999) has provided evidence of gender discrimination in the workplace. Typically arguments focus on role congruity theory, which posits that individuals face discrimination when they behave contrary to prescribed societal roles (Eagly \& Karau, 2002). However, by introducing PCST, our study broadens the scope of gender discrimination and shows how women can even be punished for behavior that is open to ambiguous interpretation.

\section{Limitations and Directions for Future Research}

The conclusions of this study must be considered in light of several limitations. One is our methodology. Laboratory research has the potential to reduce generalizability and introduce questions of ecological validity. In this setting, participants had no previous interactions with the manager and rated job performance based on observing one presentation. It may be that these results are specific to first impressions or only hold when individuals have little information about the actor (e.g., employee selection contexts). If the evaluator has seen the humorous female arriving early, staying late, or otherwise contributing to team performance, then perhaps the gender stereotype will fail to influence humor interpretation, and positive outcomes of humor 
will be present for both males and females. Unfortunately, even if female leaders can cancel out these negative effects by providing additional high performance signals, women would be required to meet a high performance standard before receiving the benefits of humor. The benefit of investigating our ideas in a controlled environment is the opportunity to test these effects when work experience, background, and performance are kept constant. Our results provide evidence that, all things equal, reactions to successful humor depend on the gender of the source.

A second limitation is the context of the evaluation. Popular advice suggests that humor improves presentation effectiveness (Kushner, 2003, 2004), which suggests that our research context demonstrates applicability. However, as a result, our context is a more formal setting, and participants were asked to deliberately evaluate performance. This differs from casual, impromptu conversations where individuals can interject humor. Authentic, in-conversation humor may introduce a different evaluation process that is characterized by intuitive information processing. This difference may be important because research comparing the effect of deliberative and intuitive thinking suggests that intuitive thinking can produce more altruistic decision making guided by empathy (Zhong, 2011). Thus, one potential area of future research is to consider more casual work contexts, where being funny may produce universal benefits.

We also recommend that future studies expand upon ways in which stereotypes may alter the interpretation of ambiguous behavior. For example, employee volunteering, which is largely beneficial to employee performance, can be perceived as being driven by intrinsic or instrumental motives, with more positive impressions associated with individuals who are perceived to be intrinsically motivated (Rodell \& Lynch, 2016). The female stereotype of affiliation may increase the likelihood that volunteering is perceived as being motivated by an 
intrinsic motivation to help for women. Conversely, the male stereotype of agency may increase the likelihood that volunteering is perceived as being motivated by instrumental reasons for men. Practical Implications and Conclusion

Given the association of humor with positive outcomes, it is natural for organizational leaders to seek ways to incorporate humor into workplace interactions (Romero \& Cruthirds, 2006). Existing research supports the idea that this strategy can improve employee satisfaction and performance (Avolio et al., 1999; Decker, 1987). In fact, management training scholars have argued that humor represents an effective charismatic leadership tactic (Antonakis, Fenley, \& Liechti, 2012), and popular books on how to win over audiences advocate for humor (Gallo, 2014). However, our findings suggest that this perspective requires a note of caution. The potential for women to advance in the workplace may be harmed by the use of humor. Thus, recommending the use of humor to women leaders may in fact reduce their perceived effectiveness and opportunities for career advancement.

That said, increased awareness of prejudice can help reduce its occurrence. The prejudice habit-breaking framework suggests that implicit biases can be reduced by learning about contexts that activate the bias and how to replace biased responses with non-prejudicial ones (Devine, 1989; Devine, Monteith, Zuwerink, \& Elliot, 1991). When individuals who endorse nonprejudicial values learn that they have acted with bias, they are motivated to inhibit the expression of prejudice and act to break the habit (Amodio, Devine, \& Harmon-Jones, 2007; Monteith, 1993; Plant \& Devine, 2009) and can even reduce implicit biases long-term (Devine, Forscher, Austin, \& Cox, 2012). We recommend that intervention programs incorporate these findings to identify when prejudice may exist and thus help reduce potential negative outcomes. 
Fewer than 5\% of Fortune 500 CEOs are female (Zarya, 2018), and research has sought to identify potential reasons why. Consistently, scholars have shown that the same behavior is interpreted differently for men and women (e.g., Heilman \& Chen, 2005; Heilman \& Haynes, 2005; Judiesch \& Lyness, 1999). We extend this work and identify humor as a potential source of gender-based inequality at work. The results of the present investigation indicate that even when women successfully express humor, they experience a reduction in status perceptions, performance evaluations, and assessments of leadership capability. Given the importance of identifying contexts that activate biases in the process of prejudice reduction (Devine, 1989; Devine et al., 2012; Devine et al., 1991), we hope that identifying this undesired dynamic can help make progress toward the goal of achieving greater equality in the workplace. 


\section{REFERENCES}

Amodio, D. M., Devine, P. G., \& Harmon-Jones, E. (2007). A dynamic model of guilt: Implications for motivation and self-regulation in the context of prejudice. Psychological Science, 18(6), 524-530.

Anderson, C., Brion, S., Moore, D. A., \& Kennedy, J. A. (2012). A status-enhancement account of overconfidence. Journal of Personality and Social Psychology, 103(4), 718-735.

Anderson, C., \& Kilduff, G. J. (2009). The pursuit of status in social groups. Current Directions in Psychological Science, 18(5), 295-298.

Antonakis, J., Fenley, M., \& Liechti, S. (2012). Learning charisma. Transform yourself into the person others want to follow. Harvard Business Review, 90(6), 127-130.

Apte, M. L. (1985). Humor and laughter: An anthropological approach. Ithaca, NY: Cornell University Press.

Avolio, B. J., Howell, J. M., \& Sosik, J. J. (1999). A funny thing happened on the way to the bottom line: Humor as a moderator of leadership style effects. Academy of Management Journal, 42(2), 219-227.

Bauer, D. J., Preacher, K. J., \& Gil, K. M. (2006). Conceptualizing and testing random indirect effects and moderated mediation in multilevel models: New procedures and recommendations. Psychological Methods, 11(2), 142-163.

Bitterly, T. B., Brooks, A. W., \& Schweitzer, M. E. (2017). Risky business: When humor increases and decreases status. Journal of Personality and Social Psychology, 112(3), 431.

Bizi, S., Keinan, G., \& Beit-Hallahmi, B. (1988). Humor and coping with stress: A test under real-life conditions. Personality and Individual Differences, 9(6), 951-956. 
Blader, S. L., \& Chen, Y.-R. (2014). What's in a name? Status, power, and other forms of social hierarchy. In J. T. Cheng, J. L. Tracy, \& C. Anderson (Eds.), The psychology of social status (pp. 71-95). New York, NY: Springer.

Blair, I. V., Judd, C. M., \& Fallman, J. L. (2004). The automaticity of race and Afrocentric facial features in social judgments. Journal of Personality and Social Psychology, 87(6), 763778.

Blair-Loy, M. (2004). Work devotion and work time Fighting for time: Shifting boundaries of work and social life (pp. 282-316): Russell Sage Publications New York.

Bunderson, J. S. (2003). Recognizing and utilizing expertise in work groups: A status characteristics perspective. Administrative Science Quarterly, 48(4), 557-591.

Cann, A., \& Matson, C. (2014). Sense of humor and social desirability: Understanding how humor styles are perceived. Personality and Individual Differences, 66, 176-180.

Caudron, S. (1992). Humor is healthy in the workplace. Personnel Journal, 71(6), 63-63.

Chattopadhyay, P., Tluchowska, M., \& George, E. (2004). Identifying the ingroup: A closer look at the influence of demographic dissimilarity on employee social identity. Academy of Management Review, 29(2), 180-202.

Chen, Y.-R., Peterson, R. S., Phillips, D. J., Podolny, J. M., \& Ridgeway, C. L. (2012). Introduction to the special issue: Bringing status to the table — attaining, maintaining, and experiencing status in organizations and markets. Organization Science, 23(2), 299-307.

Cialdini, R. B., Borden, R. J., Thorne, A., Walker, M. R., Freeman, S., \& Sloan, L. R. (1976). Basking in reflected glory: Three (football) field studies. Journal of Personality and Social Psychology, 34(3), 366-375. 
Cooper, C. (2008). Elucidating the bonds of workplace humor: A relational process model. Human Relations, 61(8), 1087-1115.

Cooper, C. D. (2005). Just joking around? Employee humor expression as an ingratiatory behavior. Academy of Management Review, 30(4), 765-776.

Correll, S. J., \& Ridgeway, C. L. (2006). Expectation states theory. Handbook of Social Psychology, 29-51.

Csikszentmihalyi, M. (1996). Creativity: Flow and the psychology of discovery and invention. New York: Harper/Collins.

Darley, J. M., \& Gross, P. H. (1983). A hypothesis-confirming bias in labeling effects. Journal of Personality and Social Psychology, 44(1), 20-33.

Decker, W. H. (1987). Managerial humor and subordinate satisfaction. Social Behavior and Personality, 15(2), 225-232.

Devine, P. G. (1989). Stereotypes and prejudice: Their automatic and controlled components. Journal of Personality and Social Psychology, 56(1), 5-18.

Devine, P. G., Forscher, P. S., Austin, A. J., \& Cox, W. T. L. (2012). Long-term reduction in implicit race bias: A prejudice habit-breaking intervention. Journal of Experimental Social Psychology, 48(6), 1267-1278.

Devine, P. G., Monteith, M. J., Zuwerink, J. R., \& Elliot, A. J. (1991). Prejudice with and without compunction. Journal of Personality and Social Psychology, 60(6), 817-830.

Diekman, A. B., \& Eagly, A. H. (2000). Stereotypes as dynamic constructs: Women and men of the past, present, and future. Personality and Social Psychology Bulletin, 26(10), 11711188. 
Djurdjevic, E., Stoverink, A. C., Klotz, A. C., Koopman, J., Veiga, S. P. D., Yam, K. C., \& Chiang, J. T. J. (2017). Workplace status: The development and validation of a scale. Journal of Applied Psychology, 102(7), 1124-1147.

Duncan, W. J., Smeltzer, L. R., \& Leap, T. L. (1990). Humor and work: Applications of joking behavior to management. Journal of Management, 16(2), 255-278.

Eagly, A. H., \& Karau, S. J. (2002). Role congruity theory of prejudice toward female leaders. Psychological review, 109(3), 573.

Eagly, A. H., Karau, S. J., \& Makhijani, M. G. (1995). Gender and the effectiveness of leaders: a meta-analysis. Psychological Bulletin, 117(1), 125-145.

Eagly, A. H., Makhijani, M. G., \& Klonsky, B. G. (1992). Gender and the evaluation of leaders: A meta-analysis. Psychological Bulletin, 111(1), 3-22.

Ellemers, N., De Gilder, D., \& Haslam, S. A. (2004). Motivating individuals and groups at work: A social identity perspective on leadership and group performance. Academy of Management Review, 29(3), 459-478.

Epitropaki, O., \& Martin, R. (2004). Implicit leadership theories in applied settings: Factor structure, generalizability, and stability over time. Journal of Applied Psychology, 89(2), 293-310.

Fineman, S. (2006). On being positive: Concerns and counterpoints. Academy of Management Review, 31(2), 270-291.

Finkelstein, L. M., Cerrentano, C. A., \& Voyles, E. C. (2016). Humor and person perception. In R. Christopher (Ed.), The psychology of humor at work: A psychological perspective (pp. 28-44): Taylor and Francis Ltd. 
Fiske, S. T., \& Berdahl, J. (2007). Social power. In A. W. Kruglansk \& E. T. Higgins (Eds.), Social psychology: Handbook of basic principles (Vol. 2, pp. 678-692). New York, NY: Guilford.

Fiske, S. T., Cuddy, A. J. C., Glick, P., \& Xu, J. (2002). A model of (often mixed) stereotype content: Competence and warmth respectively follow from perceived status and competition. Journal of Personality and Social Psychology, 82(6), 878-902.

Gallo, C. (2014). Talk like TED: the 9 public speaking secrets of the world's top minds (First: March 2014 ed.). New York: St. Martin's Press.

Galloway, G. (2010). Individual differences in personal humor styles: Identification of prominent patterns and their associates. Personality and Individual Differences, 48(5), 563-567.

Graffin, S. D., Wade, J. B., Porac, J. F., \& McNamee, R. C. (2008). The impact of CEO status diffusion on the economic outcomes of other senior managers. Organization Science, $19(3), 457-474$

Grugulis, I. (2002). Nothing serious? Candidates' use of humour in management training. Human Relations, 55(4), 387-406.

Hardy, C. L., \& Van Vugt, M. (2006). Nice guys finish first: The competitive altruism hypothesis. Personality and Social Psychology Bulletin, 32(10), 1402-1413.

Hayes, A. F. (2015). An index and test of linear moderated mediation. Multivariate Behavioral Research, 50(1), 1-22.

Heilman, M. E. (2012). Gender stereotypes and workplace bias. Research in Organizational Behavior, 32, 113-135. 
Heilman, M. E., Block, C. J., \& Stathatos, P. (1997). The affirmative action stigma of incompetence: Effects of performance information ambiguity. Academy of Management Journal, 40(3), 603-625.

Heilman, M. E., \& Chen, J. J. (2005). Same behavior, different consequences: reactions to men's and women's altruistic citizenship behavior. Journal of Applied Psychology, 90(3), 431.

Heilman, M. E., \& Haynes, M. C. (2005). No credit where credit is due: Attributional rationalization of women's success in male-female teams. Journal of Applied Psychology, $90(5), 905-916$

Hekman, D. R., Johnson, S. K., Foo, M.-D., \& Yang, W. (2017). Does diversity-valuing behavior result in diminished performance ratings for non-white and female leaders? Academy of Management Journal, 60(2), 771-797.

Hentschel, T., Heilman, M. E., \& Peus, C. (2013). Have perceptions of women and men changed? Gender stereotypes and self-ratings of men and women. Paper presented at the Presentation at the society of personality and social psychology annual conference.

Judiesch, M. K., \& Lyness, K. S. (1999). Left behind? The impact of leaves of absence on managers' career success. Academy of Management Journal, 42(6), 641-651.

Koch, A. J., D'Mello, S. D., \& Sackett, P. R. (2015). A meta-analysis of gender stereotypes and bias in experimental simulations of employment decision making. Journal of Applied Psychology, 100(1), 128-161.

Koenig, A. M., Eagly, A. H., Mitchell, A. A., \& Ristikari, T. (2011). Are leader stereotypes masculine? A meta-analysis of three research paradigms. Psychological Bulletin, 137(4), 616-642. 
Kuiper, N. A., \& McHale, N. (2009). Humor styles as mediators between self-evaluative standards and psychological well-being. The Journal of Psychology, 143(4), 359-376.

Kuiper, N. A., McKenzie, S. D., \& Belanger, K. A. (1995). Cognitive appraisals and individual differences in sense of humor: Motivational and affective implications. Personality and Individual Differences, 19(3), 359-372.

Kunda, Z., \& Sherman-Williams, B. (1993). Stereotypes and the construal of individuating information. Personality and Social Psychology Bulletin, 19(1), 90-99.

Kunda, Z., \& Thagard, P. (1996). Forming impressions from stereotypes, traits, and behaviors: A parallel-constraint-satisfaction theory. Psychological review, 103(2), 284.

Kushner, M. (2003). Presentations for dummies. Somerset: John Wiley \& Sons, Incorporated.

Kushner, M. (2004). Public speaking for dummies (2 ed.). Somerset: For Dummies.

Magee, J. C., \& Galinsky, A. D. (2008). Social hierarchy: The self - reinforcing nature of power and status. Academy of Management Annals, 2(1), 351-398.

Malone, P. B. (1980). Humor: A double-edged tool for today's managers? Academy of Management Review, 5(3), 357-360.

Martin, R. A., \& Dobbin, J. P. (1989). Sense of humor, hassles, and immunoglobulin A: Evidence for a stress-moderating effect of humor. The International Journal of Psychiatry in Medicine, 18(2), 93-105.

Martin, R. A., Puhlik-Doris, P., Larsen, G., Gray, J., \& Weir, K. (2003). Individual differences in uses of humor and their relation to psychological well-being: Development of the Humor Styles Questionnaire. Journal of Research in Personality, 37(1), 48-75.

McGraw, A. P., \& Warren, C. (2010). Benign violations: Making immoral behavior funny. Psychological Science, 21(8), 1141-1149. 
Mesmer-Magnus, J., Glew, D. J., \& Viswesvaran, C. (2012). A meta-analysis of positive humor in the workplace. Journal of Managerial Psychology, 27(2), 155-190.

Monteith, M. J. (1993). Self-regulation of prejudiced responses: Implications for progress in prejudice-reduction efforts. Journal of Personality and Social Psychology, 65(3), 469485.

Motro, D., \& Ellis, A. P. J. (2017). Boys, don’t cry: Gender and reactions to negative performance feedback. Journal of Applied Psychology, 102(2), 227-235.

Muthén, L. K., \& Muthén, B. O. (1998-2017). Mplus User’s Guide (Eighth Edition ed.). Los Angeles, CA: Muthén \& Muthén.

Newstrom, J. W. (2002). Makihng work fun: An important role for managers. SAM Advanced Management Journal, 67(1), 4-8.

Nezu, A. M., Nezu, C. M., \& Blissett, S. E. (1988). Sense of humor as a moderator of the relation between stressful events and psychological distress: A prospective analysis. Journal of Personality and Social Psychology, 54(3), 520-525.

O’Quin, K., \& Derks, P. (1997). Humor and creativity: A review of the empirical literature Creativity Research Handbook (Vol. 1, pp. 227-256). Cresskill, NJ: Hampton Press.

Plant, E. A., \& Devine, P. G. (2009). The active control of prejudice: Unpacking the intentions guiding control efforts. Journal of Personality and Social Psychology, 96(3), 640-652.

Preacher, K. J., Rucker, D. D., \& Hayes, A. F. (2007). Addressing moderated mediation hypotheses: Theory, methods, and prescriptions. Multivariate Behavioral Research, $42(1), 185-227$ 
R. Core Team. (2017). R: A language and environment for statistical computing. Vienna, Austria: R Foundation for Statistical Computing. Retrieved from https://www.Rproject.org/

Rivera, L. A., \& Tilcsik, A. (2016). Class advantage, commitment penalty: The gendered effect of social class signals in an elite labor market. American Sociological Review, 81(6), 1097-1131.

Rodell, J. B., \& Lynch, J. W. (2016). Perceptions of employee volunteering: Is it "credited" or "stigmatized" by colleagues? Academy of Management Journal, 59(2), 611-635.

Romero, E. J., \& Cruthirds, K. W. (2006). The use of humor in the workplace. The Academy of Management Perspectives, 20(2), 58-69.

Rosette, A. S., Leonardelli, G. J., \& Phillips, K. W. (2008). The White standard: racial bias in leader categorization. Journal of Applied Psychology, 93(4), 758.

Rosette, A. S., \& Tost, L. P. (2010). Agentic women and communal leadership: How role prescriptions confer advantage to top women leaders. Journal of Applied Psychology, 95(2), 221-235.

Sagar, H. A., \& Schofield, J. W. (1980). Racial and behavioral cues in Black and White children's perceptions of ambiguously aggressive acts. Journal of Personality and Social Psychology, 39(4), 590-598.

Sande, G. N., Ellard, J. H., \& Ross, M. (1986). Effect of arbitrarily assigned status labels on selfperceptions and social perceptions: The mere position effect. Journal of Personality and Social Psychology, 50(4), 684-689.

Taylor, P., \& Bain, P. (2003). 'Subterranean worksick blues': Humour as subversion in two call centres. Organization Studies, 24(9), 1487-1509. 
Westwood, R. I., \& Johnston, A. (2013). Humor in organization: From function to resistance. Humor, 26(2), 219-247.

Willer, R. (2009). Groups reward individual sacrifice: The status solution to the collective action problem. American Sociological Review, 74(1), 23-43.

Yam, K. C., Christian, M., Wei, W., Liao, Z., \& Nai, J. (2018). The mixed blessing of leader sense of humor: Examining costs and benefits. Academy of Management Journal, 61(1), 348-369.

Zarya, V. (2018). The share of female CEOs in the Fortune 500 dropped by 25\% in 2018. Fortune. Retrieved from http://fortune.com/2018/05/21/women-fortune-500-2018/

Zhong, C.-B. (2011). The ethical dangers of deliberative decision making. Administrative Science Quarterly, 56(1), 1-25. 


\begin{abstract}
APPENDIX
Four videos were generated according to the 2 (humor: yes vs. no) $\times 2$ (male vs. female) between-subjects design. Each video was less than four minutes. The two humorous videos were used for Sample 1, and all four videos were used for Sample 2. All the videos were filmed by a professional videographer. One actress and one actor, selected from a pool of university students majoring in drama, played the role of the store manager. They were selected from a pool of candidates based on their similarity in age (early twenties) and appearance (skin tone, perceived physical attractiveness, and hair color). Two individuals (one male and one female) played the role of regional managers and were used for all four videos. The presentation was filmed such that the camera was focused on the presenter. Only a portion of the back of their heads of the regional managers was visible. All four videos followed the same script, with the exception of the humorous statements included in the humor conditions. Table A1 includes all five humorous statements.
\end{abstract}

The videos began with a short introduction from the presenter. There were four slides in the presentation (introduction, two content slides, and conclusion). The content slides included both positive and negative information about store performance during the last quarter, and the presenter responded to questions from the regional managers. After showing the concluding slide, the presenter provided some final comments and invited the regional managers to ask any additional questions. The video ended after the regional managers indicated that they did not have any questions. Participants were required to watch the entire video before responding to any study measures. 
Table A1

Non-humorous condition

I appreciate your willingness to meet with me today. I think I have some interesting and useful points to discuss about the last quarter.

Yes, that is something I have thought about a lot. Unfortunately, the answer is most likely a result of the more global trend of fewer mall customers. As I talk with the other store managers in the Towne Center Mall, they describe very similar trends happening in their stores. So, it seems like the success of Amazon.com and other online retailers is contributing to this trend.

That's a good question. I don't have specific data to support my claim, but I have implemented some specific initiatives with my team of sales associates that have likely contributed to this trend.

That's a good point. I don't want them to feel like I'm overly scrutinizing them or breathing over their shoulder. So, the format of these meetings will be primarily focused on getting feedback from the employee on their questions and struggles and then I can tailor my response and coaching to their needs and desires.

Well, that concludes my presentation. Are there any remaining questions for me?

\section{Humorous condition}

So, last night, my wife/husband gave me some good advice about this presentation. She/he said whatever you do don't try to be too charming, witty, or intellectual... just be yourself!

Yes, that is something I have thought about a lot. Unfortunately, the answer is most likely a result of online retailers reducing the number of mall customers. In fact, recently another store manager in the mall was telling me about how Amazon.com is really making things difficult with impressive new features such as delivery by drones ... and I had to agree ... I mean it's going to be much cooler to say that your package was shot down rather than just stolen from your porch. But, anyway, the point is that we do have a largescale trend of fewer mall customers across the board.

That's a good question. I don't have any specific data to support my claim .... and ... perhaps that's OK because $27 \%$ of statistics are made up anyway ... but I have implemented some specific initiatives with my team of sales associates that have likely contributed to this trend.

That's a good point. I don't want them to feel like I'm always breathing over their shoulder ... too much of that and they'll start complaining 'there's no better vacation than my boss being on vacation,' right? ... So, the format of these meetings will be primarily focused on getting feedback from the employee on their questions and struggles and then I can tailor my response and coaching to their needs and desires.

I like to jokingly advise people that if you can't convince them, then you just need to confuse them. Hopefully my presentation hasn't been too confusing. Are there any final questions? 
Table 1

Means, standard deviations, and correlations for Sample 1 variables and experimental conditions

\begin{tabular}{|c|c|c|c|c|c|}
\hline Variable & 1 & 2 & 3 & 4 & 5 \\
\hline \multicolumn{6}{|l|}{ 1. Presenter gender } \\
\hline 2. Disruptiveness & .17 & & & & \\
\hline 3. Functionality & $-.21 *$ & $-.83 * *$ & & & \\
\hline 4. Employee attractiveness & $.44^{* *}$ & -.04 & .12 & & \\
\hline 5. Participant gender & .09 & -.09 & .07 & .12 & \\
\hline Descriptive statistics, $M(S D)$ & $.51(.50)$ & $2.41(1.64)$ & $5.43(1.57)$ & $5.05(1.30)$ & $.39(.49)$ \\
\hline Humorous male condition & & $2.13(1.52)$ & $5.77(1.37)$ & & \\
\hline Humorous female condition & & $2.69(1.71)$ & $5.10(1.70)$ & & \\
\hline
\end{tabular}

Note. $\quad N=96$. Presenter gender was coded as $0=$ male, $1=$ female. Participant gender was coded as $0=$ male, $1=$ female. All other variables were measured on a scale from 1-7. ${ }^{*} p<.05$. ${ }^{* *} p<.01$. 
Table 2

Means, standard deviations, and correlations for Sample 2 variables and experimental conditions

\begin{tabular}{|c|c|c|c|c|c|c|c|}
\hline Variable & 1 & 2 & 3 & 4 & 5 & 6 & 7 \\
\hline \multicolumn{8}{|l|}{ 1. Gender } \\
\hline 2. Humor & -.01 & & & & & & \\
\hline 3. Status & $-.23 * *$ & -.00 & & & & & \\
\hline 4. Performance evaluation & $-.29 * *$ & -.05 & $.60 * *$ & & & & \\
\hline 5. Leadership capability & $-.35^{* *}$ & -.04 & $.68 * *$ & $.69 * *$ & & & \\
\hline 6. Employee attractiveness & $.27 * *$ & -.01 & $.22 *$ & $.14 *$ & $.20 * *$ & & \\
\hline 7. Participant gender & .02 & -.04 & $.13^{*}$ & .13 & $.14^{*}$ & .01 & \\
\hline Descriptive statistics, $M(S D)$ & $.49(.50)$ & $.49(.50)$ & $5.07(1.27)$ & $5.27(1.24)$ & $5.87(1.02)$ & $4.77(1.45)$ & $.42(.49)$ \\
\hline Non-humorous male condition & & & $5.14(1.10)$ & $5.58(1.60)$ & $6.10(0.70)$ & & \\
\hline Humorous male condition & & & $5.59(0.96)$ & $5.67(1.09)$ & $6.33(0.66)$ & & \\
\hline Non-humorous female condition & & & $5.01(1.16)$ & $5.07(1.29)$ & $5.71(1.03)$ & & \\
\hline Humorous female condition & & & $4.50(1.59)$ & $4.72(1.32)$ & $5.29(1.29)$ & & \\
\hline
\end{tabular}

Note. $\quad N=216 . S D$ s are in parentheses. Employee gender was coded as $0=$ male, $1=$ female. Humor was coded as $0=a b s e n t, 1=$ present. Participant gender was coded as $0=$ male, $1=$ female. All other variables were measured on a scale from 1-7.

$* p<.05$. ** $p<.01$. 
Table 3

Fit statistics for nested models for Sample 2

\begin{tabular}{lcccc}
\hline \multicolumn{1}{c}{$\chi^{2}$} & $\Delta \chi^{2}$ & CFI & SRMR \\
\hline 3 factor & $\chi^{2}(51)=141.38^{* * *}$ & & .96 & .06 \\
2 factor & $\chi^{2}(53)=244.65 * * *$ & $\Delta \chi^{2}(2)=103.27 * * *$ & .92 & .06 \\
1 factor & $\chi^{2}(54)=613.40^{* * *}$ & $\Delta \chi^{2}(3)=472.02 * * *$ & .78 & .11 \\
\hline
\end{tabular}

Note. $\quad N=216.3$ factor $=$ all items loaded onto separate status, performance evaluation, and leadership capability assessment factors. 2 factor $=$ items for performance evaluation and leadership capability assessment were combined into one factor. $\mathrm{CFI}=$ comparative fit index. $\mathrm{SRMR}=$ standardized root mean squared residual. $* * * p<.001$. 
Table 4

Moderated mediation analysis: Effects of humor and gender on performance evaluation and leadership capability through status

\begin{tabular}{|c|c|c|c|c|c|c|}
\hline \multirow[b]{2}{*}{ Predictors } & \multicolumn{2}{|c|}{ Mediator $=$ Status } & \multicolumn{2}{|c|}{ DV $=$ Performance Evaluation } & \multicolumn{2}{|c|}{ DV $=$ Leadership Capability } \\
\hline & $B$ & $S E_{B}$ & $B$ & $S E_{B}$ & $B$ & $S E_{B}$ \\
\hline Intercept & $3.82 * *$ & .33 & $2.29 * *$ & .37 & $2.97 * *$ & .35 \\
\hline Attractiveness & $.27 * *$ & .06 & .01 & .04 & .04 & .04 \\
\hline Participant Gender & $.33 * *$ & .16 & .12 & .14 & .09 & .10 \\
\hline Humor & $.46^{*}$ & .19 & -.11 & .13 & -.07 & .10 \\
\hline Gender & -.35 & .21 & - & - & - & - \\
\hline Humor $\times$ Gender & $-.94 * *$ & .31 & - & - & - & - \\
\hline Status & - & - & $.58 * *$ & .06 & $.53 * *$ & .05 \\
\hline Direct and indirect effects & Coefficient & $95 \% \mathrm{CI}$ & Coefficient & $95 \% \mathrm{CI}$ & Coefficient & $95 \% \mathrm{CI}$ \\
\hline Direct effect of humor & - & - & $-.11(.13)$ & $-.36, .16$ & $-.07(.10)$ & $-.27, .12$ \\
\hline Indirect effect of humor & - & - & $-.10(.17)$ & $-.43, .22$ & $-.06(.14)$ & $-.34, .19$ \\
\hline \multicolumn{7}{|l|}{ Conditional effects } \\
\hline Men & $.46^{*}(.22)$ & $.10, .83$ & - & - & - & - \\
\hline Women & $-.48 *(.25)$ & $-.99,-.01$ & - & - & - & - \\
\hline \multicolumn{7}{|l|}{ Conditional indirect effects } \\
\hline Men & - & - & $.27 *(.11)$ & $.06, .50$ & $.25 *(.10)$ & $.06, .46$ \\
\hline Women & - & - & $-.28 *(.15)$ & $-.59,-.01$ & $-.26 *(.14)$ & $-.56,-.01$ \\
\hline Index of moderated mediation & - & - & $.55 * *(.19)$ & $.21, .94$ & $.50 * *(.18)$ & $.18, .88$ \\
\hline
\end{tabular}

Note. $N=216$. Coefficients presented are unstandardized estimates. $S E$ s are in parentheses. CI $=$ confidence interval.

$* p<.05 . * * p<.01$. 


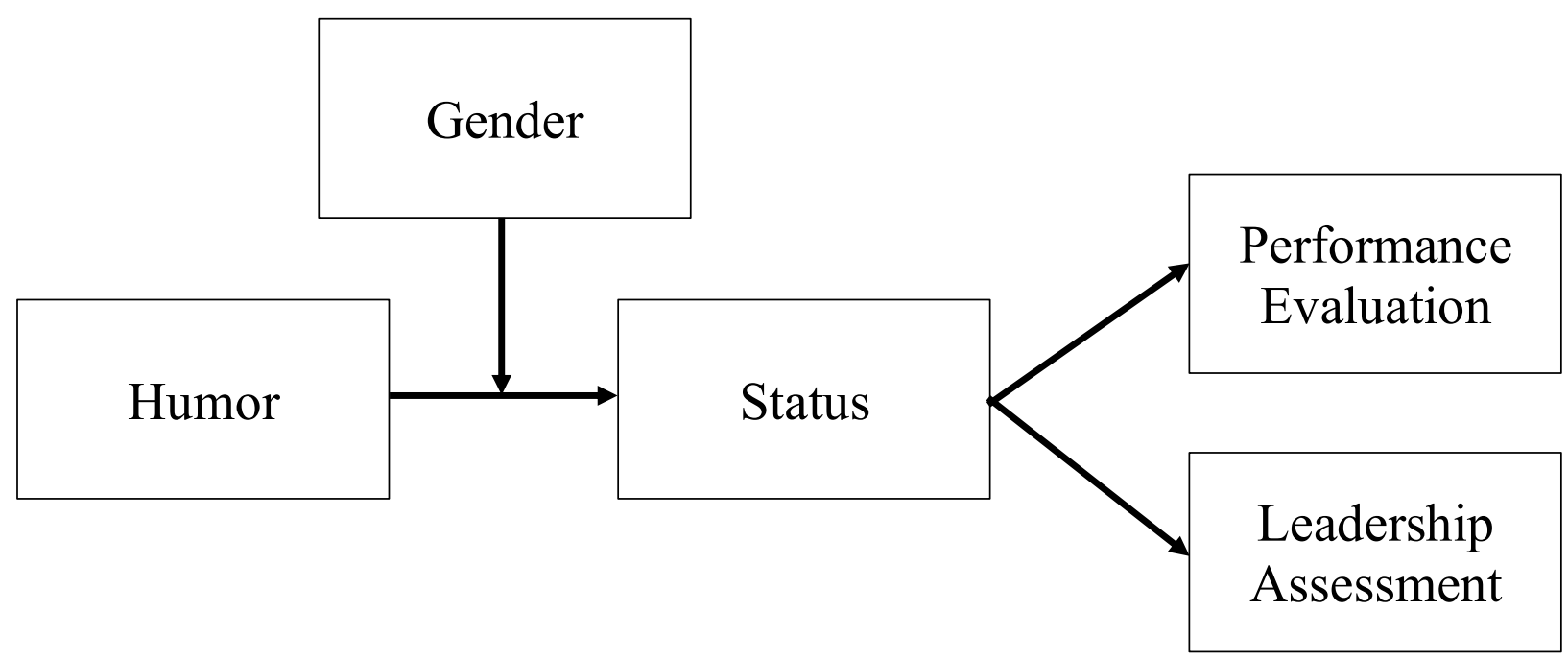

Figure 1. Influence of humor and gender on status, performance evaluation, and leadership assessment.

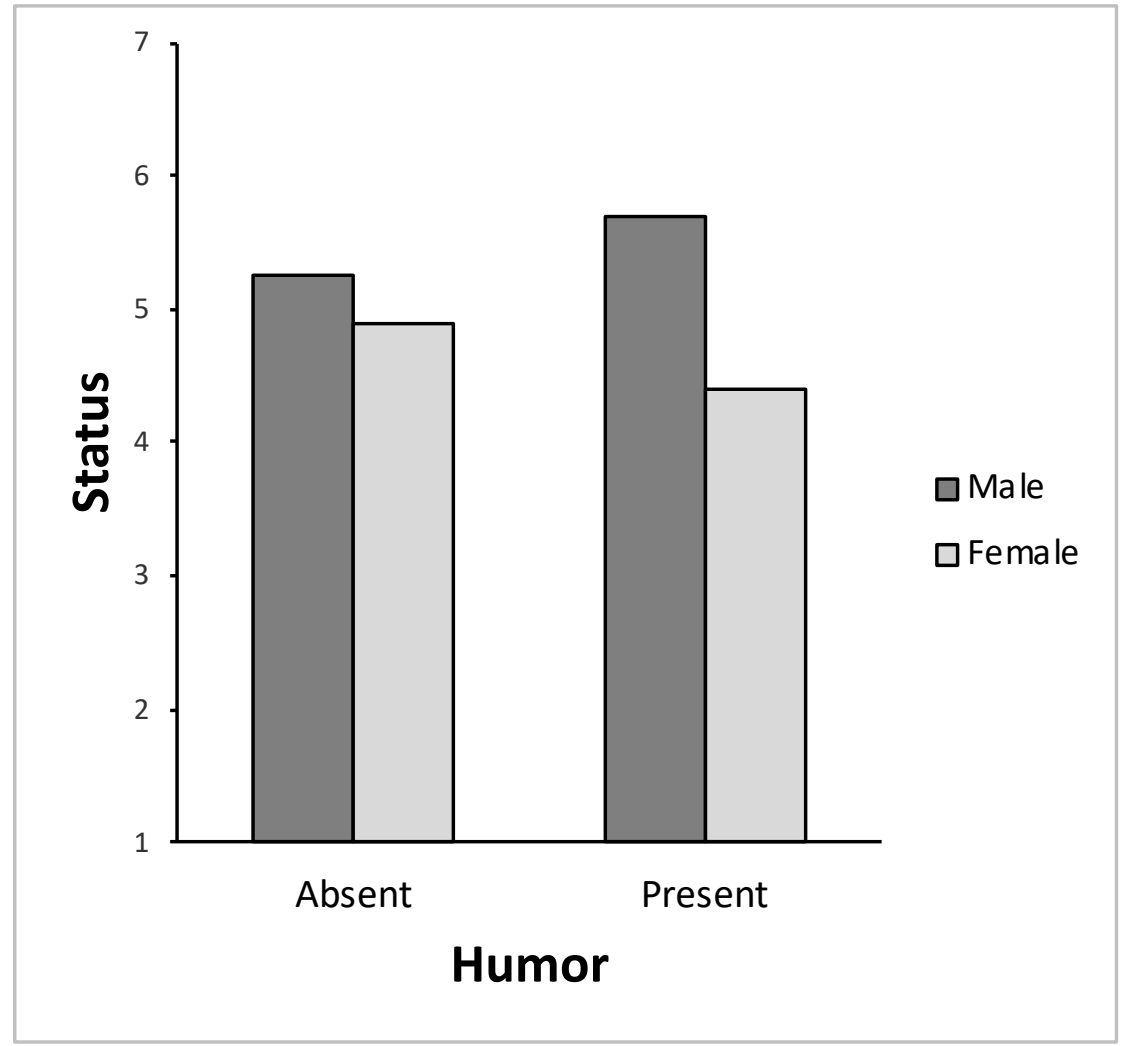

Figure 2. Interaction between humor and gender on status with attractiveness and participant gender statistically controlled. 